\title{
Multi-scale analysis by SEM, EBSD and X-ray diffraction of deformation textures of a copper wire drawn industrially
}

\author{
M. Zidani ${ }^{1}$, S. Messaoudi ${ }^{1}$, F. Dendouga ${ }^{1}$, T. Baudin $^{2,3}$, C. Derfouf ${ }^{1}$, A. Boulagroun ${ }^{1}$ \\ and M.-H. Mathon ${ }^{2}$ \\ ${ }^{1}$ Laboratoire de Génie Energétique et Matériaux, LGEM. Département de Génie Mécanique, \\ Université de Biskra, BP. 145, 07000 Biskra, Algérie \\ ${ }^{2}$ ECNRS, UMR8182, ICMMO, Laboratoire de Physico-chimie de l'Etat Solide, 91405 Orsay, France \\ ${ }^{3}$ Univ. Paris Sud, 91405 Orsay, France \\ ${ }^{4}$ Laboratoire Léon Brillouin, CEA (DSM-DRECAM)-CNRS, CEA Saclay, 91191 Gif-sur-Yvette, France
}

\begin{abstract}
In this study, we tried to understand the texture evolution of deformation during the cold drawing of copper wire (99.26\%) Drawn by the company ENICAB destined for electrical cabling and understand its link with the electrical conductivity. Characterisations performed show the appearance and texture development during the reduction of section of the wire. The texture is mainly composed of the fiber $<111>/ / \mathrm{DN}$ (DN / / drawing axis) (majority) and the fiber $<001>/ /$ ND (minority) whose acuity increases with deformation level. The wire was performed for the main components of the texture, ie the fiber $<100>$ and $<111>$ conventionally present in these materials. We will pay particular attention on the energy of the cube component $\{100\}<001>$ recrystallization that develops when the level of reduction is sufficient. There was also an increase in hardness and electrical resistivity along the applied deformation.
\end{abstract}

\section{INTRODUCTION}

During the plastic deformation of a polycrystalline material, the grains are subjected to rotations that change their crystallographic orientation. These rotations depend on the mode of deformation imposed and activated slip systems in each grain. These changes in grain orientation in the material generate to the formation of deformation texture [1]. There are several types of texture that can be encountered in the wire: fiber texture, cyclical texture and texture type single crystal [2]. Son in the fcc structure of drawn wires, the textures observed are mainly composed of an alliance in varying proportions of two components fiber $<001>$ and $<111>$ [3]. The challenge for manufacturers and scientists is the mastery of mechanical and electrical characteristics of the wire obtained. To this end, we realized this work in objective to expand the state of knowledge acquired since 2002 [4] on steels and to understand the phenomenon of formation of deformation texture scale granular and also to understand the relation between electrical conductivity and the structural orientation of new material.

\section{MATERIAL AND METHODS OF CHARACTERIZATION}

The studied material is the commercial copper wire $(\mathrm{Cu}$ : 99, $26 \%$, initial section So $=8.00 \mathrm{~mm}$ ) to different level of reduction $\left(\varepsilon_{1}=40,55 \%, \varepsilon_{2}=67,34 \%\right.$ and $\varepsilon_{3}=90$, $58 \%)$; it has been provided by the company ENICAB (Biskra-Algeria) Table 1.

Different techniques have been used for this investigation: Scanning Electron Microscopy (SEM) observations of the wire were made along the longitudinal section after etching with (Acids Nitric concentred 55\%). In order
Table 1. Results of chemical analysis of studied material $(\mathrm{Cu}$ : $99,26 \%$ ) determined by the Laboratory-ERIS company Seriana(Batna-Algeria).

\begin{tabular}{|l|l|}
\hline Main impurities & \% \\
\hline$[\mathrm{Fe}]$ & 0.021 \\
\hline$[\mathrm{Zn}]$ & 0.003 \\
\hline$[\mathrm{Ni}]$ & $<0.0044$ \\
\hline$[\mathrm{Pb}]$ & $<0.04$ \\
\hline
\end{tabular}

to evaluate the mechanical properties of the wire, Microhardness measurement (with a force of $300 \mathrm{~g}$ and electrical resistivity evolution were performed. Specimens were prepared for Electron Back Scattered Diffraction (EBSD) analysis in the standard manner. A Zeiss 940 SEM with a tungsten filament was used. The SEM device is coupled with the automatic OIM ${ }^{\mathrm{TM}}$ (Orientation Imaging Microscopy) software, from the TSL Company. X-ray diffraction (FDP and ODF) was used to examine the change in preferred grain orientation.

\section{EVOLUTION OF (MECHANICAL/ELECTRICAL) PROPRIETIES}

The metallographic analysis by SEM shows elongated grains along the drawing axis. When the level of deformation increases, the wire acquires a fibrous microstructure "Figure 1". Microhardness measurements "Figure 2" show an increase in the hardness of the wire with the level of deformation. This increase is very strong in the first stage of deformation then tends to stabilize. There was also an increase in electrical resistivity along the applied deformation "Figure 3". This type of result has already been met on wire drawn (copper/steel) [5-7]. 
A
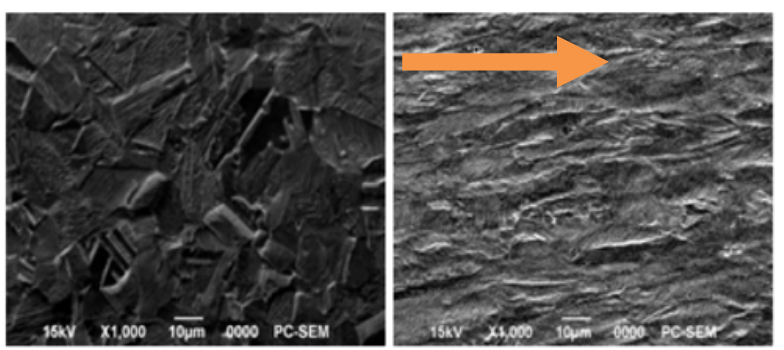

Figure 1. (SEM) Microstructures of initial (a) and drawn wires $\left(\varepsilon_{2}=67,34 \%\right)(\mathrm{b})$.

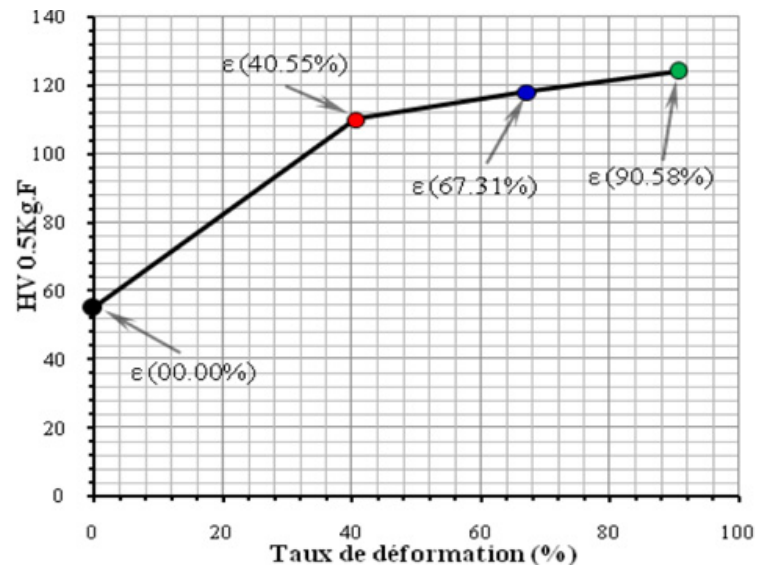

Figure 2. Vickers Microhardness curve of the copper wire after cold wiredrawing.

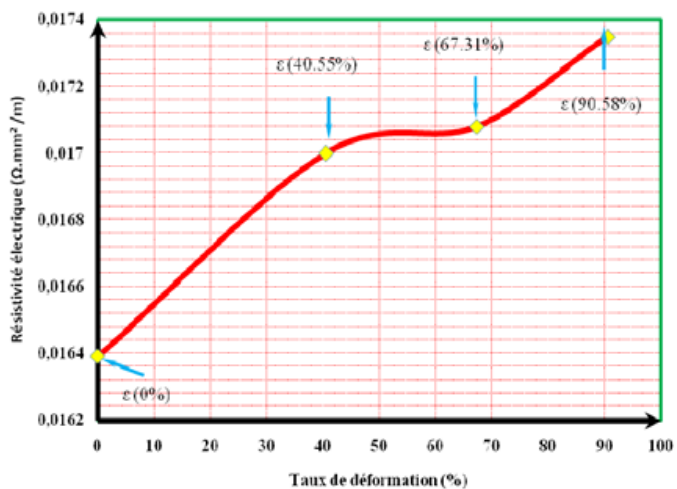

Figure 3. Resistivity measurement of the copper wire after deformation.

\section{EVOLUTION OF DEFORMATION TEXTURES}

The EBSD characterizations of wires deformed by drawing shows that the grain size depends on the level of deformation, the finer grains are obtained for the strongly drawn wire "Figure 4b" [2,3]. On the other hand "Figure 4" presents the $\{011\}$ pole figures measured by $\mathrm{X}$-ray diffraction. In the case of the initial wire (nondeformed) "Figure 4a", the intensity of the pole figures is weak ( $\mathrm{Max}=2,00$ for the $\{011\}$ pole figure), then the texture is nearly isotropic. On the contrary, the texture acuity increases with the deformation level "Figure 4b"
A
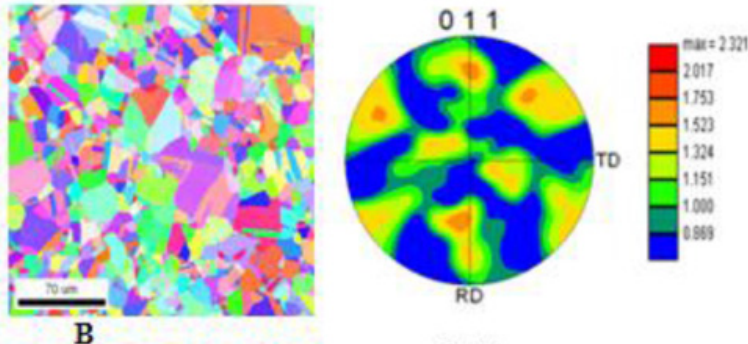

011
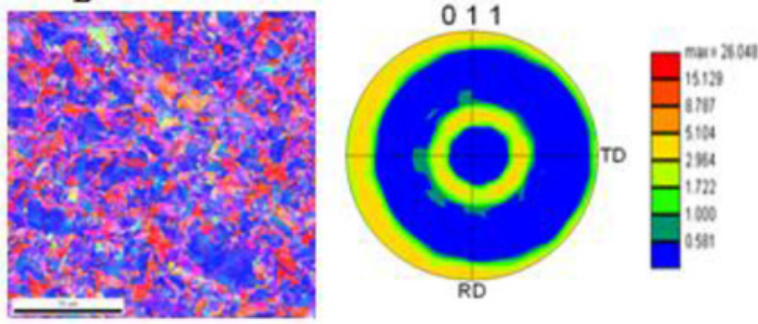

Figure 4. EBSD microstructure and $\{011\}$ pole figures (X-Ray diffraction): (A) of as-received wire and (B) after reduction by wire drawing $\left(\varepsilon_{2}=90,58 \%\right)$.

a)

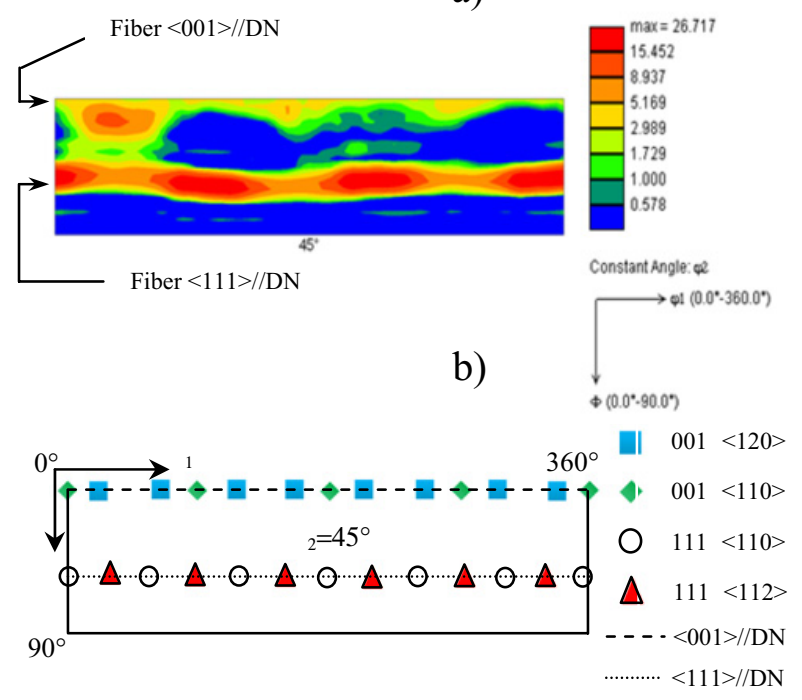

Figure 5. a) Cutting $\varphi_{2}=45^{\circ}$ to the ODF calculated after cold drawing $(90,58 \%)$ b) Positions of ideal orientations.

(Max $=26,00$ for the $\{011\}$ pole figure). These results are consistent with works done by Jakani and Gangli et al. $[8,9]$ on the wire drawn textures of copper and low carbon steels.

The texture of deformation is mainly composed of the fiber $<111>/ / \mathrm{DN}$ (DN / / drawing axis) (majority) and the fiber $<001>/ /$ ND (minority) "Figure 5a". The fiber $<001>/ / \mathrm{DN}$ is made of a reinforcement $\{001\}$ $<110>$ which is convoluted with the component $\{001\}$ $<120>$. Furthermore, we observe that the fiber $<111>$ / / DN consists of a main reinforcement of the component $\{111\}<112>$, this component is very pronounced and extends on each side almost to the component $\{111\}$ $<110>$ "Figure 5b". 


\section{CONCLUSION}

Our investigation represents a contribution to the study of the microstructure and the texture evolution after deformation applied to industrial copper drawn-wires. The drawing process causes the development of a fibrous microstructure accompanied by increased in hardness and electrical resistivity along the applied of deformation. The deformation texture is composed of the fiber of the fiber $<111>/ / \mathrm{DN}$ (DN / / drawing axis) (majority) and the fiber $<001>/ /$ ND (minority). It was noticed that the acuity of this fiber increases according to the deformation level.

\section{References}

[1] S. He, A. Van Bael, S.Y. Li, P. Van Houtte, F. Mei, A. Sarban: Mater.Sci. and Engineering A, 346, 101-107 (2003).

[2] M. Zidani, Z. Boumerzoug, T. Baudin, R. Penelle, Mater. Sci. Forum, 514-516, 554-558 (2006).

[3] M. Zidani, Z. Boumerzoug, T. Baudin and D. Solas, Mater. Sci. Forum, 550, 447-452 (2007).
[4] M. Zidani, S. Messaoudi, T. Baudin, D. Solas and M. H. Mathon Int J Mater Form 3, p.7-11, 2010.

[5] M. Zidani, S. Messaoudi, C. Derfouf, A. Boulagroun, M. H. Mathon and T. Baudin, Evolution of mechanical and electrical properties during annealing of the copper wire drawn; AIP Conf. Proc. 1400, 579-584 (2011).

[6] M. Zidani, S. Messaoudi, T. Baudin, C. Derfouf, A. Boulagroun, M.H. Mathon and, Study of the Relation Between Microstructure and Properties (Mechanical / Electrical ) of copper wire drawing and annealed AIP Conf. Proc (to be published).

[7] S. Jakani, T. Baudin, C-H. de Novion and M-H. Mathon, "Effect of impurities on the recrystallisation texture in commercially pure copper-ETP wires" Materials Science and Engineering A, 456, 261-269 (2007).

[8] S. Jakani, Thèse de doctorat "Effet des impuretés sur les mécanismes de recristallisation du cuivre tréfilé ", Université Paris XI (2004).

[9] P.Gangli, J.A. Szpunar and Sugundo, ICOTOM 9, 531-536 (1991). 